\title{
Study on Innovation and Application of Abstract Painting Artistic Elements in Landscape Design
}

\author{
Huijuan Chang \\ School of Art and Design \\ Huanghe Science and Technology College \\ Zhengzhou, China \\ e-mail: 979069916@qq.com
}

\begin{abstract}
Rich representational form and deep spiritual connotation of abstract painting art have a huge and continuous impact on design field. Abundant thoughts and unique formal languages of various art schools provide the most direct and the most rich reference elements for design. Abstract painting art breaks through previous traditional painting art modes. Its rich modeling presentation and profound spiritual connotation provide specific and effective formal language for landscape design. The study on the creative inspiration of art language in landscape design will help to comprehend how to transfer art language into actual design language. This study uses the art language of abstract painting as the entry point, and studies its creative application method in landscape design.
\end{abstract}

Keywords-abstract painting; artistic elements; landscape design; innovation and application

\section{ABOUT ABStRACT PAINTING ART}

In 1910, a Russian painter Kandinsky created the Initial Abstract Watercolor Painting. This marks the formal appearance of abstract art on the stage of history.

Just like what Malevich said, "People who comprehend painting better will see object less. People who see the object do not comprehend the painting". The essence of abstract painting art pays more attention to spirit rather than form. Abstract painting art liberates the representation object from the confined appearance, and represent its spirit and essence with color, shape and composition.

\section{CREATIVE INSPIRATION OF ABSTRACT PAINTING ART LANGUAGE TO LANDSCAPE DESIGN}

It has been a century since the generation of abstract painting art. It has a huge and continuous impact on the design field with its rich representational form and deep spiritual connotation.

\section{A. Representational Form}

1) Abstract language of graphic composition.

The formation of abstract painting art represents that the artists have found out the way to express the "pure spirit" world with abstract language. The composing mode and modeling elements of painting have obtained breakthrough development. The landscape designer pursuing innovation is inspired by the painting of abstract artists, and starts to transform from classic composition characteristics, such as paying attention to axis, symmetry and decoration, to asymmetric, balanced and flexible plane layout. Simple composition and clear geometrical lines of abstract painting art becomes the basic feature of landscape design affected by this.

The earliest attempt of applying abstract painting art language to landscape design works can be dated back to 1927, a villa garden located in the Southern France Hyeres and designed by GaBriel Guevrekan. Thereafter, Miller Garden, designed by American landscape designer Dan Clay in 1955 , can be called a milestone landscape design works under the influence of abstract painting art. This design reasonably expands and integrates the architectural space into the surrounding landscape. The designer uses trunk as structure organization and hedge as enclosed space, to form a contrast and shape a series of outdoor functional spaces.

We can see the application of Mondrian's abstract painting art language to modern garden design from the plane drawings for the garden designed by Walter Gropius "Fig.1" and "Fig.2". The design of garden is simple and unadorned, no axis and asymmetric, but forming an integral whole with the building. Distinct geometric feature is the direct reflection of Mondrian's abstract painting art language.
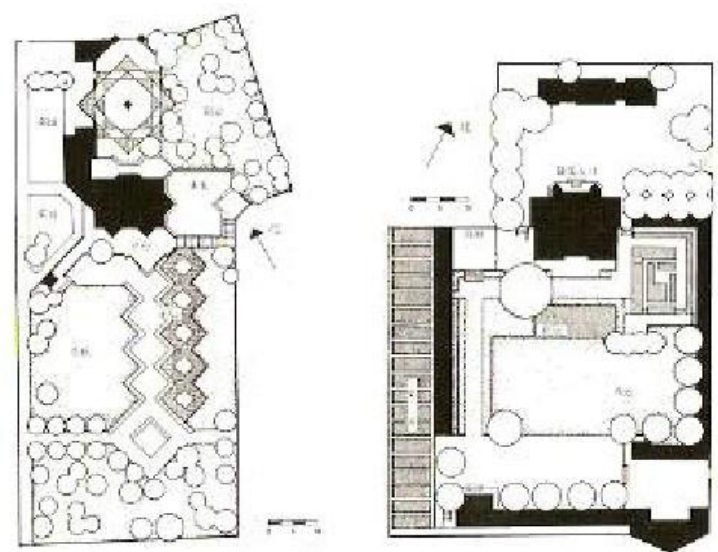

Fig. 1. Plan of garden designed by Walter Gropius 


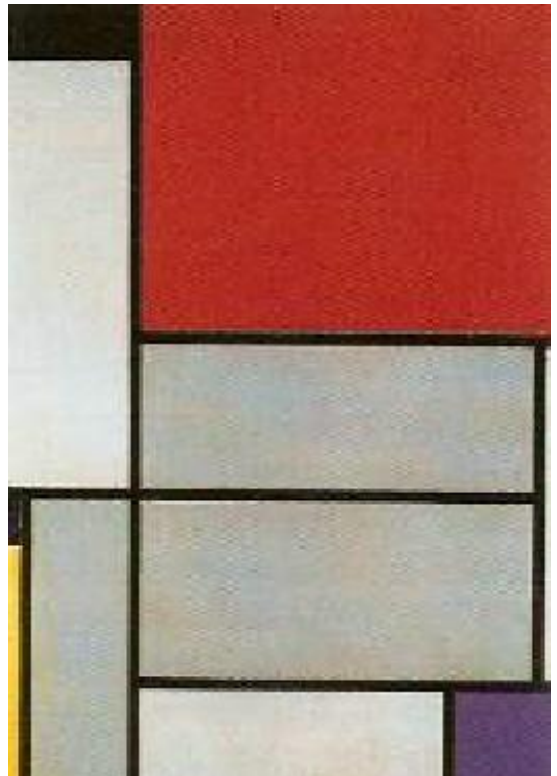

Fig. 2. Mondrian's abstract painting works

The design of contemporary avantgarde architect--Zaha Hadid is wild and exaggerated. From one of his design sketches, we can see that his thought is influenced by the suprematism of Malevich and the abstract art of Kandinsky "Fig. 3" and "Fig. 4".

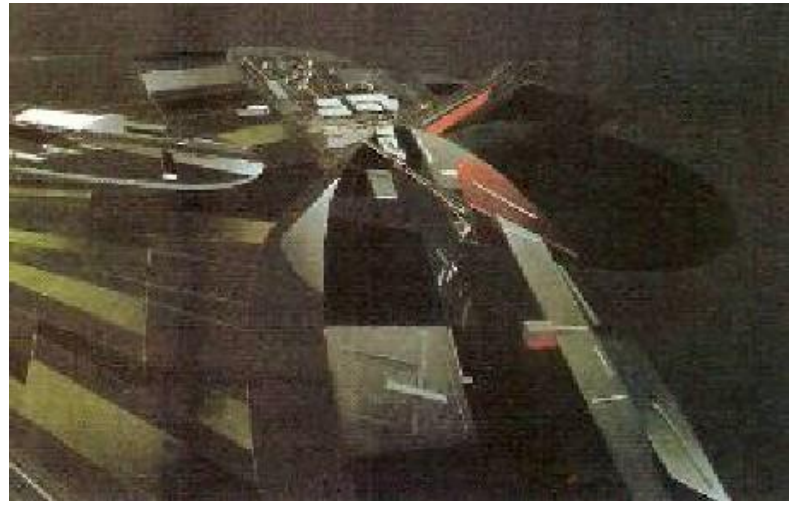

Fig. 3. Design sketch of Hadid

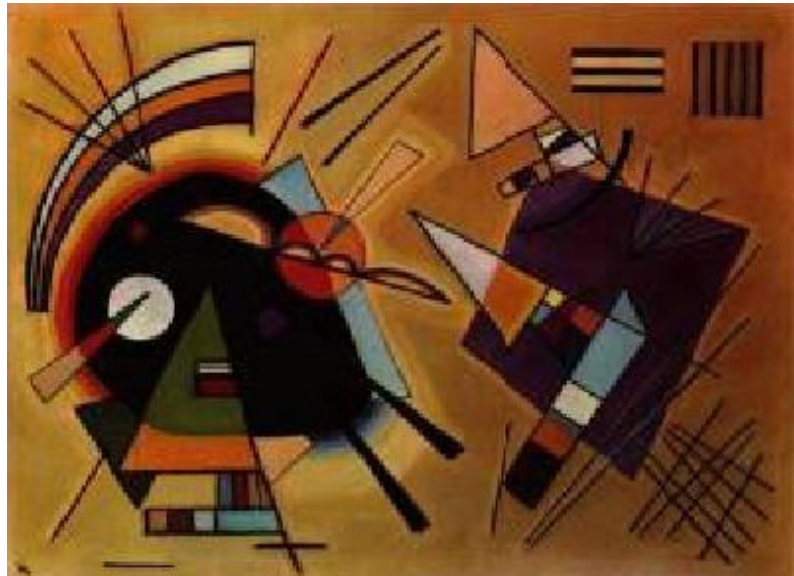

Fig. 4. Abstract painting works of Kandinsky
Kandinsky introduces a dual modeling element system to his abstract painting works, that is, black line and colorized shape. In the aspect of location distribution, the two are mutually independent, changing the linear perspective established for several centuries and the obedience of color to line. The design sketch of Zaha Hadid also adopts the dual modeling element system--invisible line and colorized shape. The location distribution is similar to the abstract painting works of Kandinsky, that is, mutual independence. In composition, the two also emphasize asymmetric, simple and lively. In use of color, both of them pursue the visual harmony of colors. Abstract works uses various bright colors to express a certain spiritual connotation, while the use of different colors by Zaha reflects a certain function.

Riem landscape park in Munich Germany plants large areas of bushes and shrubs on the flat base, therefore, large area of geometric forms are formed on the plan. Straight roads are interspersed in the form of oblique line, like a plane composition works with strong expressive force. The design has obvious features of "suprematism" painting of abstract art school "Fig. 5" and "Fig. 6". The plan of park is exactly the same as the form of painting works of Malevich-Suprematism master. Both of them adopt the composition method of dot, line and surface. Simple language of abstract painting art is reasonably transferred to the landscape design language. Grove and lake in geometric shapes, linear way, dotted isolated tree and brushwood form an extremely infectious space as abstract painting art under the careful organization of landscape designer.

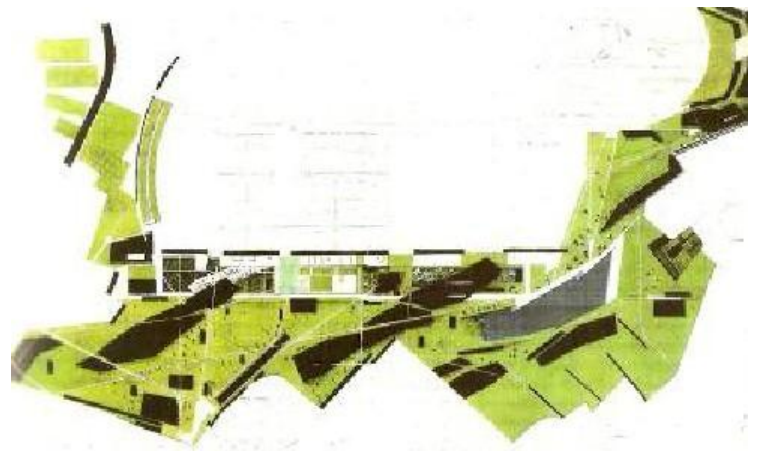

Fig. 5. Plan of Munich Riem landscape park

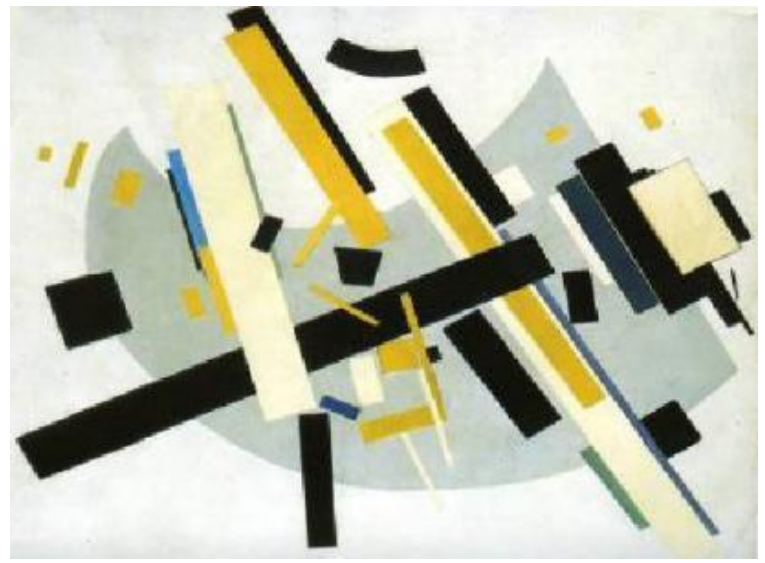

Fig. 6. Abstract painting works of Malevich 


\section{2) Perforative and penetrative space composition.}

Just as what Halprin said, "The space mutually flows without boundary." The landscape design influenced by abstract painting art pays special attention to the mutual perforation and penetration of space. Taking the landscape design of Munich Kempinski Hotel by Peter Walker as an example "Fig. 7" and "Fig. 8", its plan utilizes the superposition and insertion of many squares, and some square grids are twisted to make it seem more like a plane composition works. It also contains many features of abstract painting arts: Each space is relatively independent but forms a whole. The simple geometric pattern on the ground is emphasized. The objective of reducing perspective distortion is successfully achieved through the change of ground elevation difference. In the aspect of line font, straight line, perpendicular line and geometric shape are still used. Meanwhile, large amounts of broken lines with angle are added. The combination of line types is more freely. The asymmetric composition is adopted. The utilization of axis is not to emphasize but to arrange the scenery with partial symmetry. Or the edge of broken line is used to break the full symmetry and achieve the objective of asymmetric balance.

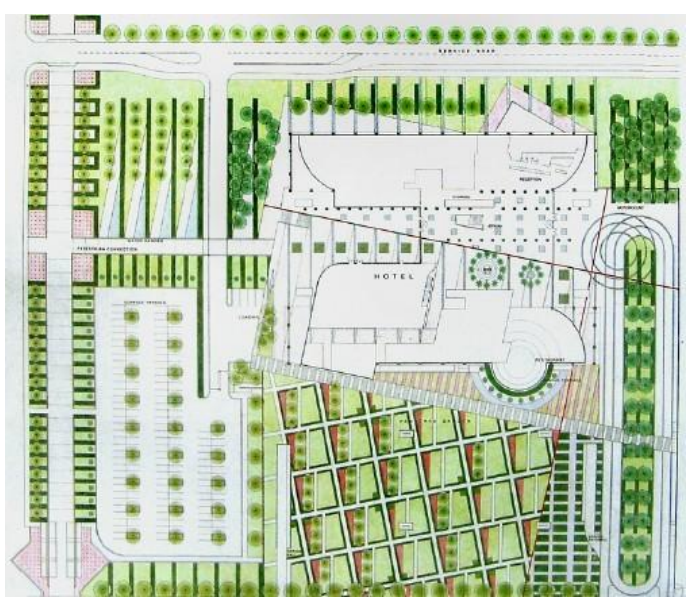

Fig. 7. Plan for the landscape design of Munich Kempinski Hotel

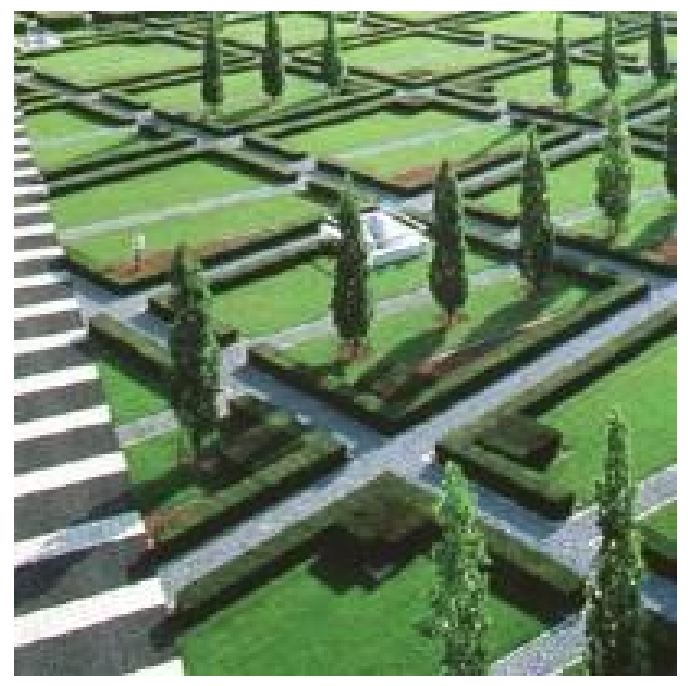

Fig. 8. Landscape design of Munich Kempinski Hotel

\section{B. Spiritual Connotation}

1) Negative decoration. The general appearance of abstract painting art has a common characteristic, that is, utilizing bright color or solid color and paying attention to composition and color balance to achieve visual harmony. In this harmony, the existence of each dot, line or color lump has its specific and necessary meaning, not for simple decorative effect. The geometric abstract image, represented by the works of Mondrian, is lively and concise. The works simultaneously uses sharply contrasted solid color or pure color, and has clear outline cutting without any transition. Through good perception of colors or precise color alignment and allocation like math, the artists arrange the overall composition and make each color unit harmoniously exist in the image.

The negative decoration spirit of abstract painting art has a certain influence on landscape design. Johnson, a senior in American Society of Landscape Architecture, recalled that, "We never set up backrest for bench, because it is uncoordinated with the whole. We try to reach 'pure'." Simpleness and pureness are the reflections of fast-pace of modern society, and straightforwardly represent the essence of object. Nothing attached exactly conforms to the aesthetic inclination of modern people "Fig. 9".

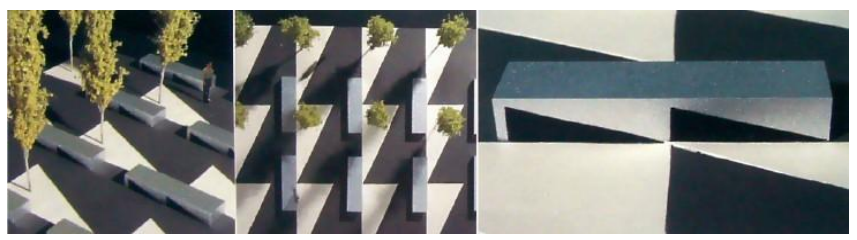

Fig. 9. Stainless steel and glass seat designed by Peter Walker in a park

2) Metaphor and symbolization. The picture meaning of abstract painting art can be divided into two types. One is the aesthetic feeling brought by the composition, geometric forms and solid color configuration. In brief, the purport and the content of this works explore the form of picture harmony. The other pays attention to the spiritual world behind the picture, that is, the image represents a certain metaphor and symbolic meaning.

Just as what Kandinsky said, "The audience must regard the picture as the reproduction of spiritual image rather than the duplicate of object." This type of abstract painting can also be called lyric abstract painting. This school regards the creation of painting as an experience and represents an essential reality combining the fantasy of heart with the experience of external world. The image created in their picture is not realistic, but depicted according to the inner feeling and phantom, or groundlessly created in other words. Therefore, the image in the picture is only vaguely discernible creature. Just as the posthumous works of Kandinsky, Safely Fly, it represents the artist's peaceful mind when he realizes that he will terminate the life and has a feeling of going up to heaven.

The symbolic meaning of image in abstract painting art is endowed by the author himself/herself. In modern landscape design, in order to reflect the natural idea and the history and 
environment of base, many designers create meaningful content and form in design through culture, form or space metaphor, and endow the landscape design with meaning to make it be easily understood.

Large and small water drop shaped earth mounds in the square in front of Minneapolis court, which are designed by Schwartz, symbolize a special local landform "drumlin"--A product after the deglaciation (Fig. 10). These earth mounds can be simply understood as hills or imagined as huge mountain. There are some log sections parallel to these earth mounds, hinting at Minnesota's forest resources attracting immigrant. Meanwhile, forestry is also a basic economy in the locality. These hints related to wood and Minnesota arouses local people's memory. Moreover, they successfully shape the distinct personality of square in urban landscape.

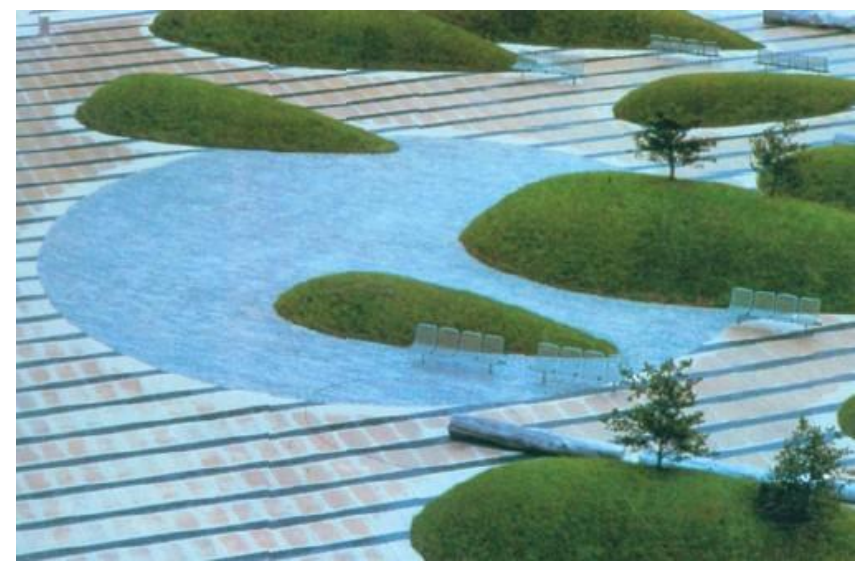

Fig. 10. Landscape of square in front of Minneapolis court

\section{CONCLUSION}

Pure art forms, such as painting and sculpture, are less affected by material, technology, society and economy. They can rapidly and keenly catch subtle change of human's conscious activity, and lead new thoughts of art. On the contrary, design field is more restricted by society and economy. Its acceptance and reflection of new art thoughts is also obviously lagging. Just because of this, the thoughts and formal language of art undoubtedly provide the most direct and the most abundant reference elements.

Of course, landscape design is not pure art form. The largest challenge for a designer is complex social problem and function problem. Landscape designer shall reasonably integrate infinitely rich art forms with actual social and functional problems. The sociality of landscape is number one after all. It is the art of the public rather than the art of a few artists.

\section{REFERENCES}

[1] Wang Xiangrong, Lin Jing. Theories and Practice of Modern Landscape Architecture in the Western World [M]. China Building Industry Press, 2002.

[2] Bao Shidu. Western Modernist Art [M]. Beijing: China Youth Publishing House, 1993.
[3] Chen Tian. An Explanation on Thoughtful Essence of Modernism Landscape Design in West [J]. Chinese Landscape Architecture, 2004(3).

[4] Chen Xiaotong. The Post-Modernism Express in the American Landscape Design [J]. Planners, 2002(6).

[5] Liu Boxin. Contemporary Western Art and Landscape Design [D]. Master Thesis of Beijing Forestry University, 2008.

[6] Chen Xi. Ideolagical Trend of American Modernism Landscape Design [D]. Master Thesis of Tianjin University, June 2003. 